\title{
Study of the Development of Higher inclusive Education in China
}

\author{
Ye Aihui*, Ma Hui \\ School of Arts and Law, Wuhan University of Technology,China \\ Email: 270371056@qq.com
}

\begin{abstract}
A nation strengthens along with its young generation. Education is no doubt important to a country and it has close relations with our daily life. However, Chinese education system is undergoing comprehensive reform. Hence, we have to form a long-term and comprehensive eyesight that although higher inclusive education is a pretty new concept, it plays a role in guaranteeing the right to education of disabled people and promoting social equity. In recent years, with the development of other countries, China is actively developing higher inclusive education.
\end{abstract}

Key words: higher inclusive education, disabled people, the development of education

\section{Higher inclusive education and its features}

In June, 1994, UNESCO approved The Programme of Action for Special Needs Education in Salamanca, Spain and it clearly put forward the concept of Higher Inclusive Education in Salamanca Statement. Inclusive education was put forward after the World War Two and aimed at the former separated education model. Hence, it is also called 'confluent education'.

Higher inclusive education is a way for disabled students to access education with common students in the same higher institute. It lays emphasis on providing common education environment for disabled students rather than a separated environment. Inclusive education has already become a world trend and has been put forward for many years overseas. Nowadays, countries like Canada, the United States, Western European countries, New Zealand and Australia make great achievements and Japan is gradually promoting it.

There are three features of higher inclusive education:

\subsection{Higher inclusive education promotes the comprehensive development of the disabled students}

Although disabled students have certain physical defects, they still have the equal right to access to higher education. Disabled students also need comprehensive development, which includes life, education and work. The willing of accessing to higher education, the wish to improve ability and the realization of individual values and social values are the basis of the comprehensive development of disable people.

\subsection{Higher inclusive education are beneficial to social stability}

Disabled students account for certain proportion in the society. Compared to common students, disabled students lie at inferior position for a long time and will form relative deprivation. Higher inclusive education is in favor of changing the present situation. Disabled students can undertake some labors with technical contents by their mental and physical strength to promote self development, decrease social risks and contribute to social stability.

\subsection{Higher inclusive education is to the benefit of the development of higher education.}

The development of higher inclusive education contributes to improve Chinese education system. It can strengthen forms of education, enrich the contents of education and promote the social development. [1]

\section{Present situation of the development of higher inclusive education in China}

\subsection{Started late but it is developing fast}

Higher education for disabled people starts late and it started since the end of 1980s in China. The implementation of the combination of higher education began in 1987. Peking University enrolled 21 disabled people for the first time. In the past 30 years, Chinese higher education achieved great success. However, it faces many challenges and 
restrictions in the process of the development. At present, educational legislation is imperfect, but it can be found from other regulations and rules. For example, Higher Education Law of the People's Republic of China (1998), National Outline for Medium and Long-term Educational Reform and Development (2010-2020) put forward "promote the introduce and implementation of disabled people, educate disabled people and the disabled people have the right to access to higher education". They guide, specify and protect the development of higher education of the disabled people from many aspects.

\subsection{Due to inadequate legislation, it needs to be developed}

During this period, although Chinese higher inclusive education achieves a lot, it still faces challenges and restrictions of the process of development. Although there are still no specific higher education laws for disabled students, the related provisions can be seen in other regulations, such as Higher Education Law of the People's Republic of China (1998), National Outline for Medium and Long-term Educational Reform and Development (2010-2020) provide guidance to disabled people from different aspects. It rules the normalization and institutionalization of the higher education of disabled people in China, protecting their right to access to higher education and promote social equality.

\section{Present situations of the development higher inclusive education overseas:}

Take Japan as an example, since the beginning of 2001, Japan began to cancel schools for the blind, the deaf and special education and changed special education to 'special supporting education' and special education schools are built to special supporting education schools and become the backbone of developing inclusive education. The diversification and difference of students enable common schools to update and put forward a series of reforms of comprehensive education, teaching and management.

Some countries establish a series of comprehensive teaching model after long-term exploration. It mainly includes three models [2]:

\subsection{Travel teacher model}

Tourist guide teacher is responsible for one area and provide special textbook, references and teaching strategy, which includes ordinary teacher education and special teacher education.

\subsection{Teaching resources model}

Like ordinary children, disable children also need their own learning time. But, we could take their individual demands into consideration to go guidance and it generally consists 1 to 3 hours per week.

\subsection{Teaching assistant model}

It means each school should not only equip teachers, but also equip specified teachers or workers to provide guidance. If necessary, they can be special education teachers. By using the complex model, special education and general education break the boundary, appeal each other and continue to combine. Besides, it also changes the coordination model of different departments and promotes the form of coordinate linkage mechanism.

\section{Suggestions on developing higher confluent education:}

According to the development patterns of higher confluent education overseas, we know it is relatively perfect. It inspires us and guides the direction:

\subsection{Common education is the power of the development of higher inclusive education}

The main reason for the success of higher confluent education overseas is that it origins from common education. Educational mode, target students and system of common education aim at common students. Under the concept of all students have the right to access to education, developed countries reform school education, aim at all kinds of students, introduce new teaching model, develop new service method and receive more teaching concepts.

Hence, we should push forward the change of teaching methods when develop common education and enable the 
diversification of teaching and make it possible to provide education for disabled students. The development of inclusive education needs the change of teaching concept during the process of reform, reform teaching methods and teaching ability.

\subsection{The influence of culture on inclusive education}

The success of the development of inclusive education of developed countries is the influence of advanced culture. Free, impartial and equality cultural values are the concepts of inclusive education. Developed countries develop inclusive education according to local conditions, formulate instructional management program in terms of the actual conditions, actively cope with the demands of students and increase the utilization of teaching resources.

Hence, we should make better teaching measures aiming at students to guarantee the success of the development of confluent education and satisfy the demands of disabled students.

\subsection{Inclusive education targets at satisfying the demands of social development}

Inclusive education is an important part of special education. It provides education for specific students and lays good foundations for their growth and provides survival skills. Inclusive education provides the chance of transforming social roles for disabled students, improves gradually and suits social development.

The main reason for the success of the development of inclusive education in the developed countries is to adjust teaching objectives and plans in terms of social demands. It not only decreases teaching costs, but also decreases the waste of teaching resources. This is one of the directions for the development of the inclusive education in China. 2]

\section{References}

[1] Ma Yu. Study on Support System of Higher Confluent Education for Disabled People in China. Nanjing Normal University, 2014, 3.

[2] Teaching models in Japan and the United States: Study on Curriculum Offering Model of Higher Vocation Education of Disabled People in China, Japan and the USA

[3] Xiong Qi. Development Process and Enlightenment of Higher Confluent Education of Disabled People in the USA. Suihua University journal,2015,10. 